Provided for non-commercial research and education use. Not for reproduction, distribution or commercial use.

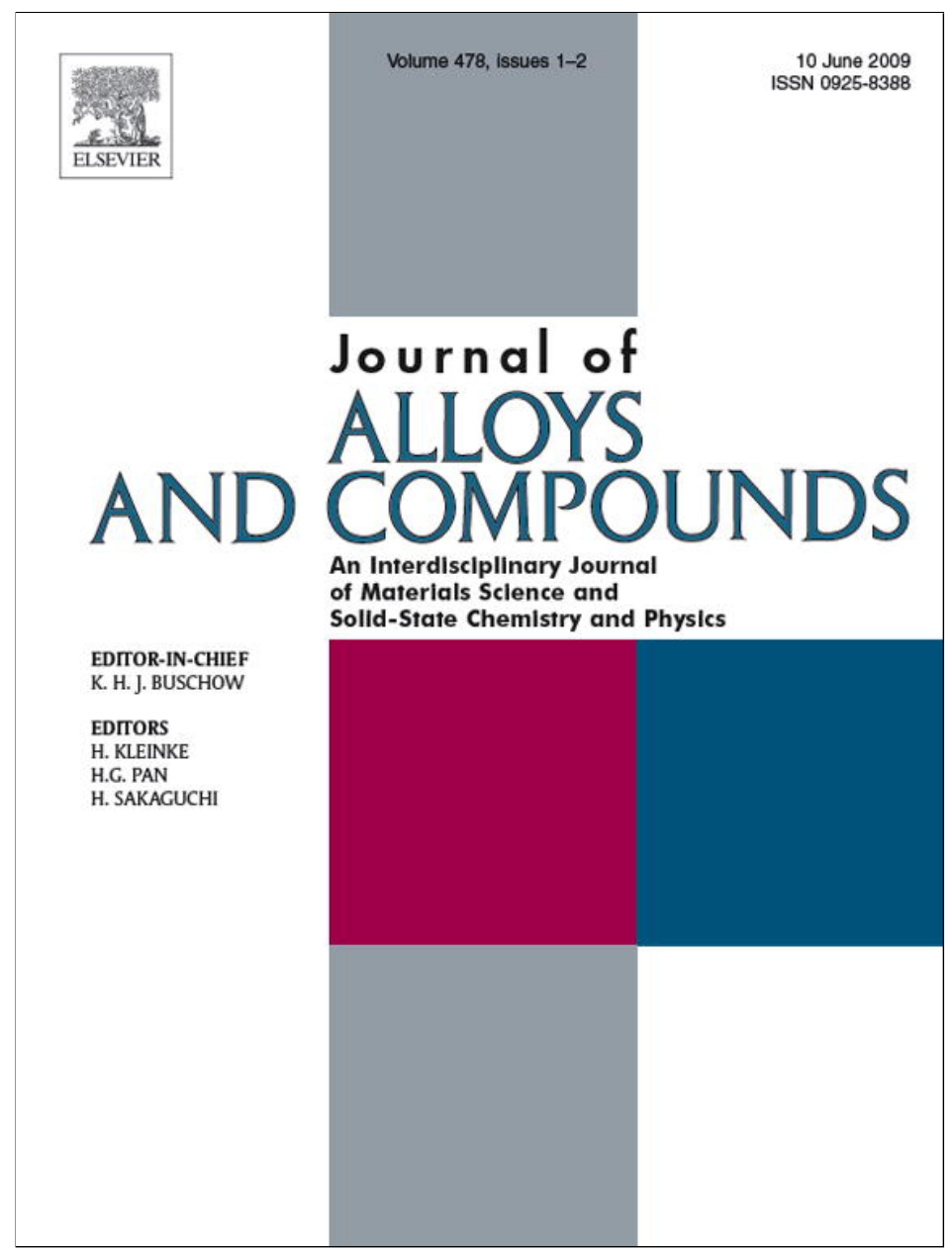

This article appeared in a journal published by Elsevier. The attached copy is furnished to the author for internal non-commercial research and education use, including for instruction at the authors institution and sharing with colleagues.

Other uses, including reproduction and distribution, or selling or licensing copies, or posting to personal, institutional or third party websites are prohibited.

In most cases authors are permitted to post their version of the article (e.g. in Word or Tex form) to their personal website or institutional repository. Authors requiring further information regarding Elsevier's archiving and manuscript policies are encouraged to visit:

http://www.elsevier.com/copyright 


\title{
Structural and magnetic properties of Cu substituted manganites studied by EXAFS and dc magnetization measurements
}

\author{
C. Castellano ${ }^{\mathrm{a}, *}$, M. Ferretti ${ }^{\mathrm{a}, \mathrm{b}}$, A. Martinelli $^{\mathrm{a}}$, M.R. Cimberle $^{\mathrm{c}}$ \\ a LAMIA-INFM-CNR, C.so Perrone 24, I-16152 Genova, Italy \\ ${ }^{\mathrm{b}}$ Dip. Chimica e Chimica Industriale, Università di Genova, Via Dodecaneso 31, I-16146 Genova, Italy \\ c CNR-IMEM c/o Dipartimento di Fisica, Via Dodecaneso 33, I-16146 Genova, Italy
}

\section{A R T I C L E I N F O}

\section{Article history:}

Received 3 July 2008

Received in revised form 10 October 2008

Accepted 16 November 2008

Available online 27 November 2008

\section{PACS:}

75.47.Lx

74.25. Ha

61.05.cj

71.30.+h

Keywords:

Oxide materials

Phase transitions

Magnetic measurements

EXAFS

\begin{abstract}
A B S T R A C T
We report extended X-ray absorption fine structure (EXAFS) measurements at the Mn K-edge and dc magnetic measurements performed on $\left(\mathrm{La}_{1-x} \mathrm{Ca}_{x}\right)\left(\mathrm{Mn}_{1-y} \mathrm{Cu}_{y}\right) \mathrm{O}_{3}$ samples $(x=0.37$ and 0.75 and $y=0.03$ or 0.08 ), thus comparing the effects determined by the partial Mn substitution with Jahn-Teller $\mathrm{Cu}^{2+}$ ions with those induced by the already studied analogous substitution of Mn with non-Jahn-Teller $\mathrm{Cr}^{3+}$.

Hence, in the present paper we complete our study on the influence of chemical Mn site substitutions on the nanoscale phase inhomogeneity characteristic of these strongly correlated electron systems.

We observe that the $\mathrm{Cu}^{2+}$ substitution determines two very different effects in the two compositions belonging from the opposite sides of the phase diagram. In the $x=0.37$ case it weakens the ferromagnetic ordering thus favouring the antiferromagnetic charge ordered phase component, while in the $x=0.75$ one it does not significantly modify the charge ordering already present in the system, differently from what previously observed in presence of non-Jahn-Teller $\mathrm{Cr}^{3+}$ substitution.
\end{abstract}

(c) 2008 Elsevier B.V. All rights reserved.

\section{Introduction}

Manganese perovskites $\left(\mathrm{La}_{1-x} \mathrm{Ca}_{x}\right) \mathrm{MnO}_{3}$ present a strong interplay between charge, lattice and spin degrees of freedom. Their phase diagram is characterized, in the range $0.20<x<0.50$, by a transition from a paramagnetic insulating phase to a ferromagnetic metallic (FM) one upon cooling [1]. Such a coupling between a magnetic phase transition and a conductive one is the basis for the so called negative colossal magnetoresistance effect (CMR) also higher than $90 \%$ in presence of a magnetic field $\mu_{0} H>1 T[1,2]$. The observation of this last effect is the main reason of the renewed interest on these compounds.

For Ca content greater than 50\% the presence of charge ordering (CO) of $\mathrm{Mn}^{3+}$ and $\mathrm{Mn}^{4+}$ ions in different sublattices is revealed at low temperature ( $T_{\mathrm{CO}}<260 \mathrm{~K}$, as a function of Ca-content). Many models have been proposed to explain the mechanisms producing the CMR effect, starting from the classical double exchange and more recently from a strong polaronic coupling of charge carriers to phonons $[2,3]$.

\footnotetext{
* Corresponding author. Tel.: +39 0103538737; fax: +39 0103628252.

E-mail address: castelc@caspur.it (C. Castellano).
}

A significant role seems also to be played by a strong spin-lattice coupling displayed by the presence around the Curie temperature $T_{\mathrm{C}}$ of magnetic polarons of about 12 Á, namely local magnetically ordered regions in an insulating matrix where the charge carrier is trapped like in a polaronic state [4]. In this last framework, experimental evidences of an inhomogeneous phase above and below $T_{C}$ where nanometric metallic and insulating domains coexist and percolate are reported in literature [4-7]. These research developments on manganites nanoscopic phase texture also point out the occurrence of further physical properties like non-volatile magnetoresistive memory at low magnetic fields and at specific chemical compositions which could allow to continue to miniaturize transistors and electronic components useful for computer engineering and spintronics applications [8]. Therefore the debate about the homogeneity of the low temperature phase and its outcomes at all Ca content is still open.

The present main research topic on these compounds is the identification of the real nature of the insulating phase component for $0.20<x<0.50$ at low $T$ in the phase separation framework; it could be a $\mathrm{CO}$ phase with a very low coherence length and therefore not detectable by lots of techniques, becoming more extended and then noticeable for $x>0.50$. In this general scenario we can reasonably assume that the partial substitution of the Mn magnetic ion could 
contribute to an enhancement of one phase component over the other [9-11]. This result should be obtained due to the strong coupling between $\mathrm{CO}$ and Jahn-Teller lattice distortion (induced by the presence of the $\mathrm{Mn}^{3+}$ ion or of its Jahn-Teller substitutes), as already evidenced by our EXAFS measurements on $\left(\mathrm{La}_{1-x} \mathrm{Ca}_{x}\right) \mathrm{MnO}_{3}$ with $x>0.50$ [12]. Another relevant effect on the conduction bandwidth and then on the magnetic exchange interaction along the partially substituted $\mathrm{Mn}^{3+}-\mathrm{O}^{2-}-\mathrm{M}$ paths can be determined by the different ionic radius of the $B$ site element in the perovskite $A B O_{3}$ structure and by the $3 \mathrm{~d}$ electronic configuration of the substituting ions (note the following ionic radii in octahedral coordination: $\mathrm{Mn}^{3+}=0.645 \AA$; $\mathrm{Mn}^{4+}=0.53 \AA ; \mathrm{Cr}^{3+}=0.615 \AA ; \mathrm{Ni}^{2+}=0.69 \AA \mathrm{Cu}^{2+}=0.73 \AA$ ).

In a previous paper [13] we pointed out how Mn-substituting $\mathrm{Cr}^{3+}$ or $\mathrm{Ni}^{2+}$ favour strengthening of the metallic-ferromagnetic phase component for $x>0.50$ since they are not associated with a Jahn-Teller distortion and act as random impurities. In this earlier case the resulting disordered Jahn-Teller distortion plays the role of a site-random or effective magnetic field weakening the Jahn-Teller CO phase $[9,10]$.

In the present paper we report the EXAFS study of local order and structure around the manganese ion on $\mathrm{Cu}^{2+}$ substituted samples $\left(\mathrm{La}_{0.63} \mathrm{Ca}_{0.37}\right)\left(\mathrm{Mn}_{0.92} \mathrm{Cu}_{0.08}\right) \mathrm{O}_{3},\left(\mathrm{La}_{0.25} \mathrm{Ca}_{0.75}\right)\left(\mathrm{Mn}_{0.92} \mathrm{Cu}_{0.08}\right) \mathrm{O}_{3}$ and $\left(\mathrm{La}_{0.25} \mathrm{Ca}_{0.75}\right)\left(\mathrm{Mn}_{0.97} \mathrm{Cu}_{0.03}\right) \mathrm{O}_{3}$. Substituting copper ions, in contrast to $\mathrm{Cr}^{3+}$ or $\mathrm{Ni}^{2+}$, should be able to strengthen the CO phase component since they are associated to a lattice Jahn-Teller distortion $\left(\mathrm{Cu}^{2+}\right.$ is characterized by a $t_{2 \mathrm{~g}}^{6} e_{\mathrm{g}}^{3}$ Jahn-Teller electronic configuration), thus completing the Mn ion site substitution scenario. We expect to observe a bigger effect in the $\left(\mathrm{La}_{0.63} \mathrm{Ca}_{0.37}\right)\left(\mathrm{Mn}_{0.92} \mathrm{Cu}_{0.08}\right) \mathrm{O}_{3}$ sample, considering that the pristine compound $\left(\mathrm{La}_{0.63} \mathrm{Ca}_{0.37}\right) \mathrm{MnO}_{3}$ is metallic and ferromagnetic below $270 \mathrm{~K}$, while on the other side of the phase diagram $\left(\mathrm{La}_{0.25} \mathrm{Ca}_{0.75}\right) \mathrm{MnO}_{3}$ exhibits $\mathrm{CO}$ below $T_{\mathrm{CO}}=225 \mathrm{~K}$.

All the samples were characterized by dc magnetization measurements and X-ray powder diffraction revealing an orthorhombic Pnma crystalline structure, and thereafter extended X-ray absorption fine structure (EXAFS) spectroscopy measurements were performed between 20 and $300 \mathrm{~K}$ at the $\mathrm{Mn} \mathrm{K}$ absorption edge. Furthermore the same samples were also investigated by neutron powder diffraction (NPD), scanning electron microscopy (SEM), transmission electron microscopy (TEM) and anelastic spectroscopy in order to investigate both the additional lattice disorder and the $\mathrm{Mn}$ average valence variation induced by $\mathrm{Cu}^{2+}$ doping.

\section{Experimental method and data analysis}

The studied samples were pellets of polycrystalline $\left(\mathrm{La}_{0.63} \mathrm{Ca}_{0.37}\right)$ $\left(\mathrm{Mn}_{0.92} \mathrm{Cu}_{0.08}\right) \mathrm{O}_{3},\left(\mathrm{La}_{0.25} \mathrm{Ca}_{0.75}\right)\left(\mathrm{Mn}_{0.92} \mathrm{Cu}_{0.08}\right) \mathrm{O}_{3}$ and $\left(\mathrm{La}_{0.25} \mathrm{Ca}_{0.75}\right)\left(\mathrm{Mn}_{0.97} \mathrm{Cu}_{0.03}\right) \mathrm{O}_{3}$ powders dispersed in a cellulose matrix optimising the jump at the absorption edge. Polycrystalline $\left(\mathrm{La}_{1-x} \mathrm{Ca}_{x}\right)\left(\mathrm{Mn}_{1-y} \mathrm{Cu}_{y}\right) \mathrm{O}_{3}$ samples were prepared by means of a solid state reaction: binary oxides ( $\mathrm{CaO}$ 99.95\% ALDRICH; $\mathrm{La}_{2} \mathrm{O}_{3} 99.99 \%$ ALFA AESAR; $\mathrm{MnO}_{2}$ 99.999\% ALFA AESAR, CuO 99.998\% ALFA AESAR) were firstly sieved ( 80 mesh), than mixed in stoichiometric amounts and finally reacted at high temperature in air. Four thermal treatments with intermediate grinding were carried out, the first at $1523 \mathrm{~K}$ for $15 \mathrm{~h}$ and the remaining at $1603 \mathrm{~K}$ for $18 \mathrm{~h}$. X-ray powder diffraction analysis (PHILIPS PW1830; Bragg-Brentano geometry; $\mathrm{CuK}_{\alpha}$; secondary monochromator; $2 \theta$ range: $13-80^{\circ}$; step: $0.020^{\circ} 2 \theta$; sampling time: $15 \mathrm{~s}$ ) did not evidence the presence of secondary phases. The Mn K-edge EXAFS data have been recorded in transmission geometry at the beamline E4 at the HASYLAB synchrotron radiation source (Hamburg) using a double-crystal $\mathrm{Si}(111)$ monochromator and a helium flux cryostat. The EXAFS oscillations $\chi(k)$ were extracted from the experimental data using standard procedures and were normalized using the Lengeler-Eisenberger method (Fig. 1) [14].

The $k^{3}$ weighted $\chi(k)$ data were Fourier transformed (FFT) in the $k$ range between 2.68 and $15.48 \AA^{-1}$ (Fig. 2). The obtained Fourier transform shows many correlation peaks up to $R=8 \AA$. The analysis was restricted to the first Mn-O coordination shell by inverse Fourier transforming the first FFT peak in the $R$ range between 0.98 and $1.96 \AA$. The so-obtained filtered data were fitted using the standard single scattering EXAFS formula and FEFF8.2 theoretical amplitude and phase functions [15]. Starting from the orthorhombic unit cell model typical of Jahn-Teller distorted manganites the FEFF code computes overlapping muffin tin spherically symmetric

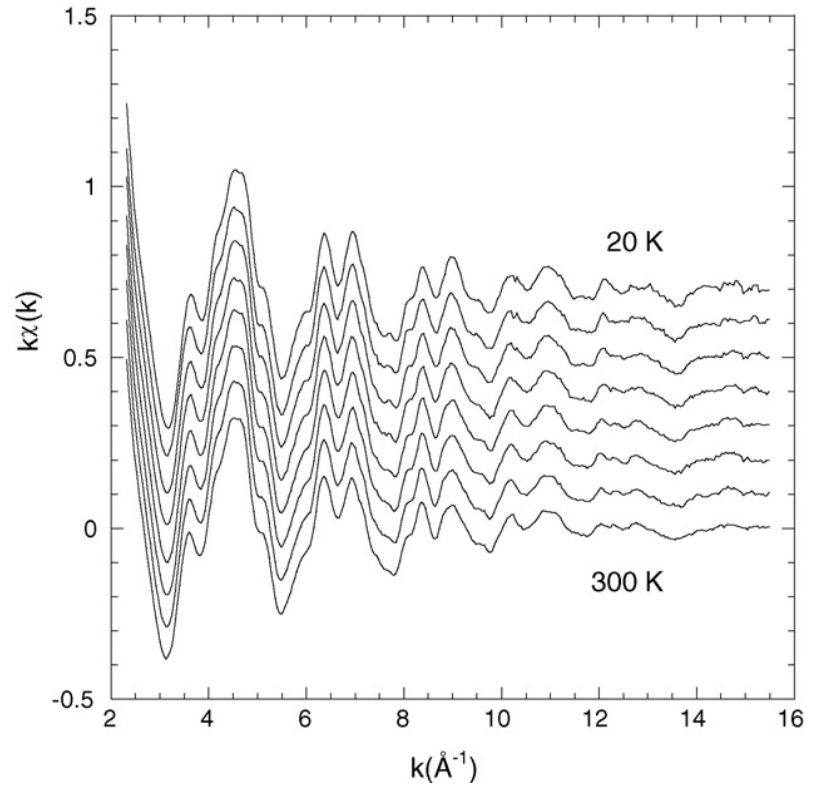

Fig. 1. EXAFS $k \chi(k)$ signal of $\left(\mathrm{La}_{0.63} \mathrm{Ca}_{0.37}\right)\left(\mathrm{Mn}_{0.92} \mathrm{Cu}_{0.08}\right) \mathrm{O}_{3}$ as a function of temperature between $20 \mathrm{~K}$ (upper curve) and $300 \mathrm{~K}$ (lower curve).

potentials and their corresponding phase-shifts thus generating the different $\mathrm{Mn}-\mathrm{O}$ path contributions in order to fit the data.

We have performed two alternative fitting procedures: at first using only one $\mathrm{Mn}-\mathrm{O}$ first shell with coordination number $N_{\mathrm{Mn}-\mathrm{O}}=6$; afterwards using two sub-shells, one corresponding to a $\mathrm{Mn}-\mathrm{O}$ coordination number $\mathrm{N}_{\mathrm{Mn}-\mathrm{O}}=4$ and the other corresponding to $N_{\mathrm{Mn}-\mathrm{O}}=2$. In particular, we considered four longer distances $R_{\mathrm{Mn}-\mathrm{O}}=2.10 \AA$ and two shorter $R_{\mathrm{Mn}-\mathrm{O}}=1.93 \AA$ at $300 \mathrm{~K}$ for the $x=0.75 \mathrm{Cu}$-substituted samples [12,13], vice versa four shorter and two longer bond lengths for the $x=0.37$ case. These starting models are the same already reported in previous papers for the corresponding un-substituted compounds $[12,13]$.

The two sub-shells fit has been possible thanks to the extension of the data in the $k$ range, the window chosen in the FFT space, the good signal to noise ratio, which enabled a sufficient number of independent fitting parameters to be used. The fitting parameters were the $\mathrm{Mn}-\mathrm{O}$ mean square relative displacements $\sigma^{2}$ and the interatomic bond lengths $\mathrm{R}_{\mathrm{Mn}-\mathrm{O}}$ both in the one shell and in the two shells analysis. The coordination numbers were fixed to the previously cited values.

In order to correctly compare the parameters behaviour as a function of temperature for the substituted and for the corresponding pristine samples, all the

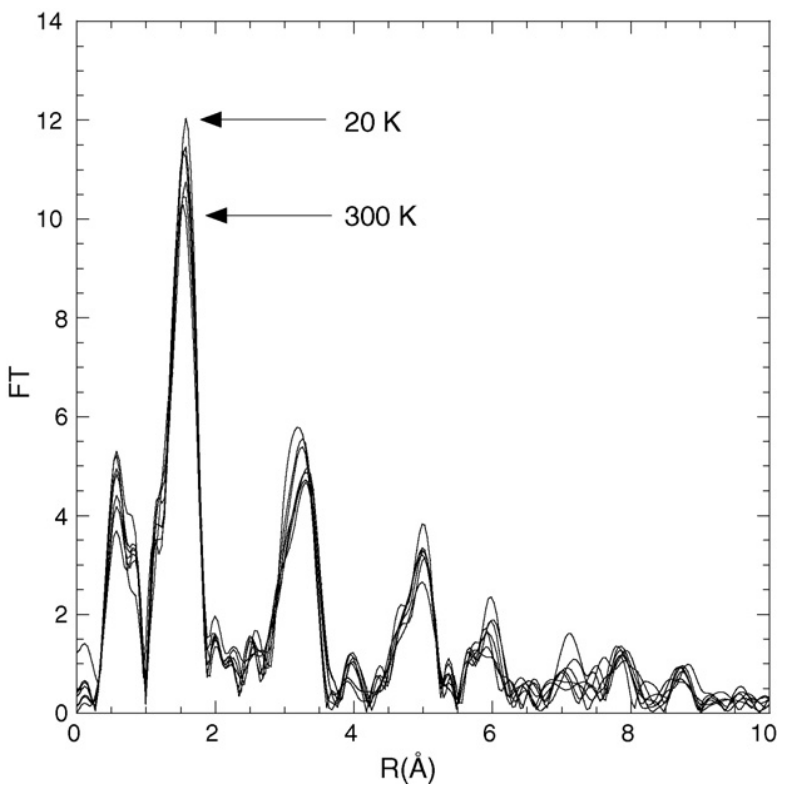

Fig. 2. Fourier transforms $\mathrm{FT}(\mathrm{R})$ of the $k^{3}$-weighted $\chi(k)$ as a function of temperature for the $\left(\mathrm{La}_{0.63} \mathrm{Ca}_{0.37}\right)\left(\mathrm{Mn}_{0.92} \mathrm{Cu}_{0.08}\right) \mathrm{O}_{3}$ sample. 


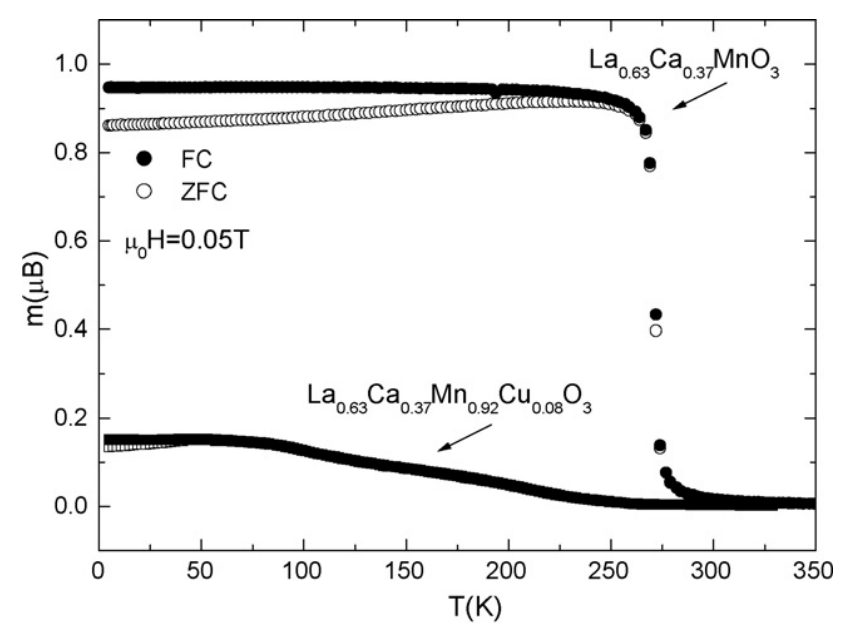

Fig. 3. Temperature dependence of ZFC (empty symbols) and FC (full symbols) dc magnetization for $\left(\mathrm{La}_{0.63} \mathrm{Ca}_{0.37}\right)\left(\mathrm{Mn}_{0.92} \mathrm{Cu}_{0.08}\right) \mathrm{O}_{3}$ (squares) and $\left(\mathrm{La}_{0.63} \mathrm{Ca}_{0.37}\right) \mathrm{MnO}_{3}$ (circles) samples.

fitting criteria in the data analysis performed on the samples were identical to those reported in previous papers $[12,13]$.

The dc magnetic measurements were performed by using a commercial magnetometer (MPMS by Quantum Design) on the same sample powders.

\section{Results and discussion}

We present a comparison of the local structure parameters around the Mn ions and magnetic properties, obtained by the EXAFS and dc magnetization studies respectively, in the Cu-substituted and pristine compounds for the cited $\mathrm{Ca}$ concentrations thus characterizing also on a local scale the Mn substitution effects on polarons and $\mathrm{CO}$ formation.

Zero field cooled (ZFC) and FC susceptibility measurements performed on both pristine and substituted samples, with $x=0.37$ and $x=0.75$ are shown in Figs. 3 and 4, respectively.

In the $\left(\mathrm{La}_{0.63} \mathrm{Ca}_{0.37}\right)\left(\mathrm{Mn}_{0.92} \mathrm{Cu}_{0.08}\right) \mathrm{O}_{3}$ sample the $\mathrm{Mn} / \mathrm{Cu}$ substitution effect is extremely marked: copper ions induce a strong distortion of the surrounding lattice both due to their Jahn-Teller nature and to their greater dimensions respect to the Mn ones. These distortions frustrate the double exchange magnetic interactions between the neighbouring $\mathrm{Mn}$ ions thus reducing the $e_{\mathrm{g}}$ electron conduction bandwidth and favouring the Mn ions superexchange interactions associated to the antiferromagnetic CO phase component (see the $m(T)$ behaviour in Fig. 3) [16]. In addition to local distortions, $\mathrm{Cu}^{2+}$ substitution induces a re-equilibration of the $\left[\mathrm{Mn}^{3+}\right] /\left[\mathrm{Mn}^{4+}\right]$ ratio determining a charge transfer effect. For example the $8 \% \mathrm{Cu}^{2+}$ content increases the average $\mathrm{Mn}$ valence from 3.37 in $\left(\mathrm{La}_{0.63} \mathrm{Ca}_{0.37}\right) \mathrm{MnO}_{3}$ to 3.49 in $\left(\mathrm{La}_{0.63} \mathrm{Ca}_{0.37}\right)\left(\mathrm{Mn}_{0.92} \mathrm{Cu}_{0.08}\right) \mathrm{O}_{3}$ approaching the boundary between the FM and $\mathrm{CO}$ long-range phases [1].

The described magnetic outcome is much more evident in $\left(\mathrm{La}_{0.63} \mathrm{Ca}_{0.37}\right)\left(\mathrm{Mn}_{0.92} \mathrm{Cu}_{0.08}\right) \mathrm{O}_{3}$, where we start from a FM macroscopic phase before substitution, while it is less marked in the

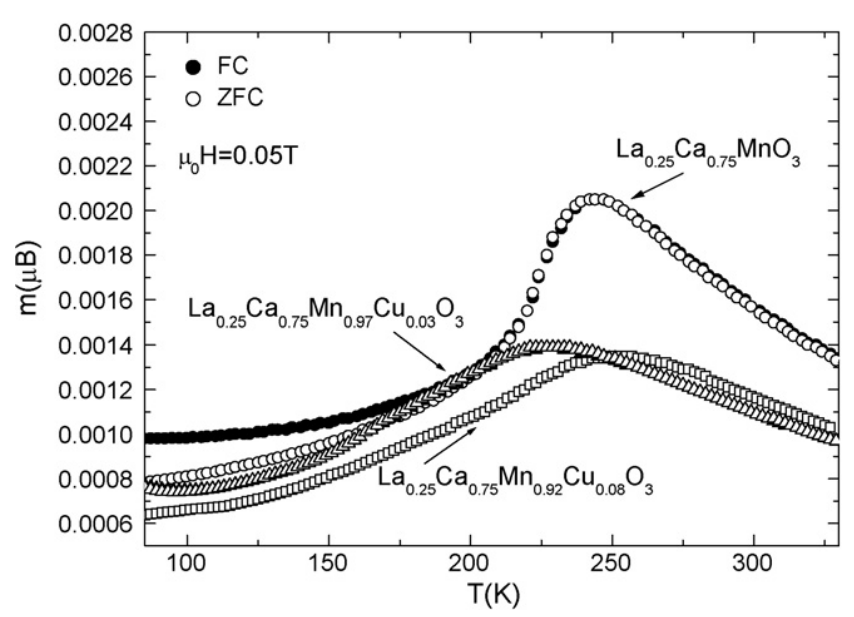

Fig. 4. Temperature dependence of susceptibility measured in $\mathrm{ZFC}$ and $\mathrm{FC}$ conditions for $\left(\mathrm{La}_{0.25} \mathrm{Ca}_{0.75}\right)\left(\mathrm{Mn}_{0.92} \mathrm{Cr}_{0.08}\right) \mathrm{O}_{3}$ (squares), ( $\left(\mathrm{La}_{0.25} \mathrm{Ca}_{0.75}\right)\left(\mathrm{Mn}_{0.97} \mathrm{Cr}_{0.03}\right) \mathrm{O}_{3}$ (triangles) and $\left(\mathrm{La}_{0.25} \mathrm{Ca}_{0.75}\right) \mathrm{MnO}_{3}$ (circles).

$\left(\mathrm{La}_{0.25} \mathrm{Ca}_{0.75}\right)\left(\mathrm{Mn}_{0.92} \mathrm{Cu}_{0.08}\right) \mathrm{O}_{3}$ and $\left(\mathrm{La}_{0.25} \mathrm{Ca}_{0.75}\right)\left(\mathrm{Mn}_{0.97} \mathrm{Cu}_{0.03}\right) \mathrm{O}_{3}$ compounds where the magnetic behaviour is completely different. For these last samples, whose pristine compound has a main $\mathrm{CO}$ and antiferromagnetic phase, the characteristic CO susceptibility drop determined by the appearance of antiferromagnetic superexchange interactions correlated with the localization of charge carriers is only weakened after Mn substitution. In this last case the $\mathrm{Cu}^{2+}$ ions act mainly as random impurities, determining an effective or siterandom magnetic field but always preserving the insulating CO long range phase, due to their Jahn-Teller nature (Fig. 4).

Therefore from a macroscopic point of view our starting hypotheses are verified: the CO non-ferromagnetic state coupled to the Jahn-Teller lattice distortion is favoured in presence of Jahn-Teller substituting ions like $\mathrm{Cu}^{2+}$.

We describe now the behaviour of the structural EXAFS parameters, firstly focusing our attention on the $\mathrm{Mn}-\mathrm{O}$ single shell results. The best-fit parameters values are reported in Table 1 for the $\left(\mathrm{La}_{0.63} \mathrm{Ca}_{0.37}\right)\left(\mathrm{Mn}_{0.92} \mathrm{Cu}_{0.08}\right) \mathrm{O}_{3}$ and $\left(\mathrm{La}_{0.25} \mathrm{Ca}_{0.75}\right)\left(\mathrm{Mn}_{0.92} \mathrm{Cu}_{0.08}\right) \mathrm{O}_{3}$ samples at $T=300 \mathrm{~K}$.

In Fig. 5 the local order parameter $\sigma^{2}$ of the $\mathrm{MnO}_{6}$ coordination shell is reported as a function of temperature for the substituted sample $\left(\mathrm{La}_{0.63} \mathrm{Ca}_{0.37}\right)\left(\mathrm{Mn}_{0.92} \mathrm{Cu}_{0.08}\right) \mathrm{O}_{3}$ (empty squares) and for the pristine $\left(\mathrm{La}_{0.63} \mathrm{Ca}_{0.37}\right) \mathrm{MnO}_{3}$ and $\left(\mathrm{La}_{0.25} \mathrm{Ca}_{0.75}\right) \mathrm{MnO}_{3}$ samples (empty triangles and full circles) which respectively belong to the long-range $\mathrm{FM}$ and $\mathrm{CO}$ representative compositions.

The EXAFS results before and after the $\mathrm{Cu}$ substitution show a clear enhancement of the local disorder as a function of $T$ in $\left(\mathrm{La}_{0.63} \mathrm{Ca}_{0.37}\right)\left(\mathrm{Mn}_{0.92} \mathrm{Cu}_{0.08}\right) \mathrm{O}_{3}$ with respect to the sudden decrease evidenced in the $\left(\mathrm{La}_{0.63} \mathrm{Ca}_{0.37}\right) \mathrm{MnO}_{3}$ sample [17,18] and to a Debyelike trend (continuous line). This striking effect is strictly connected to an enhanced $\mathrm{CO}$ phase, going towards the $\sigma^{2}$ behaviour of the charge ordered $\left(\mathrm{La}_{0.25} \mathrm{Ca}_{0.75}\right) \mathrm{MnO}_{3}$ sample [12]. We point out how the effect induced by the Jahn-Teller $\mathrm{Cu}^{2+}$ substituting ion is extremely different from that induced on the same sample com-

Table 1

Best-fit parameters obtained both from the two Mn-O sub-shells and from the single shell analysis of the $\left(\mathrm{La}_{0.63} \mathrm{Ca}_{0.37}\right)\left(\mathrm{Mn}_{0.92} \mathrm{Cu}_{0.08}\right) \mathrm{O}_{3}$ and $\left(\mathrm{La}_{0.25} \mathrm{Ca}_{0.75}\right)\left(\mathrm{Mn}_{0.92} \mathrm{Cu}_{0.08}\right) \mathrm{O}_{3}$ samples at 300 K.N is the coordination number, $S_{0}^{2}$ is the total amplitude reduction factor, $R$ is the average interatomic distance and $\sigma^{2}$ is the Debye-Waller factor. Numbers in parentheses are statistical errors in the best significant digit.

\begin{tabular}{|c|c|c|c|c|c|c|c|}
\hline \multicolumn{2}{|l|}{ Fit sub-shell } & \multicolumn{3}{|c|}{$\left(\mathrm{La}_{0.63} \mathrm{Ca}_{0.37}\right)\left(\mathrm{Mn}_{0.92} \mathrm{Cu}_{0.08}\right) \mathrm{O}_{3}$} & \multicolumn{3}{|c|}{$\left(\mathrm{La}_{0.25} \mathrm{Ca}_{0.75}\right)\left(\mathrm{Mn}_{0.92} \mathrm{Cu}_{0.08}\right) \mathrm{O}_{3}$} \\
\hline Path & $N$ & $S_{0}^{2}$ & $R(\AA)$ & $\sigma^{2} \times 10^{-3}\left(\AA^{2}\right)$ & $S_{0}^{2}$ & $R(\AA)$ & $\sigma^{2} \times 10^{-3}\left(\AA^{2}\right)$ \\
\hline $\mathrm{Mn}-\mathrm{O}$ & 4 & $0.85(1)$ & 1.93(1) & $4.5(2)$ & $0.85(1)$ & $2.10(1)$ & $4.3(2)$ \\
\hline $\mathrm{Mn}-\mathrm{O}$ & 2 & $0.85(1)$ & $2.03(1)$ & $3.6(2)$ & $0.85(1)$ & 1.93(1) & $3.3(2)$ \\
\hline Mn-O single-shell & 6 & $0.85(1)$ & $1.98(1)$ & $5.9(2)$ & $0.85(1)$ & $2.03(1)$ & $5.8(2)$ \\
\hline
\end{tabular}




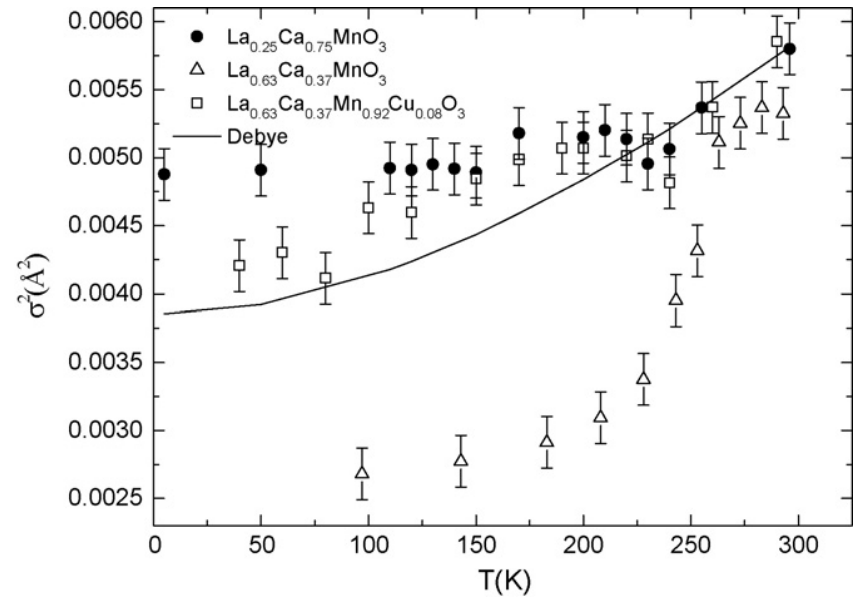

Fig. 5. Mn-O mean square relative displacement $\sigma^{2}\left(\AA^{2}\right)$ of $\left(\operatorname{La}_{0.63} \mathrm{Ca}_{0.37}\right)$ $\left(\mathrm{Mn}_{0.92} \mathrm{Cu}_{0.08}\right) \mathrm{O}_{3}$ (empty squares) and of the pristine $\left(\mathrm{La}_{0.63} \mathrm{Ca}_{0.37}\right) \mathrm{MnO}_{3}$ and $\left(\mathrm{La}_{0.25} \mathrm{Ca}_{0.75}\right) \mathrm{MnO}_{3}$ samples (empty triangles and full circles; adapted from Ref. [11]), determined from the single shell analysis as a function of temperature (the continuous line represents the Debye-like contribution to the total disorder factor).

position by non-Jahn-Teller $\mathrm{Cr}^{3+}$ and $\mathrm{Ni}^{2+}$, where we revealed (see Ref. [13]) only a progressive broadening and lowering of the PM-FM transition determined by the fact that these cationic species do not participate in double exchange. Moreover, we have also to consider that the cited charge transfer effect induced by the Mn substitution with a divalent ion is not sufficient to determine the huge effect observed both in magnetic and structural properties only in the Jahn-Teller $\mathrm{Cu}^{2+}$ case and not in the $\mathrm{Ni}^{2+}$ one [13]. Therefore the local Jahn-Teller distortion coupled to the $\mathrm{CO}$ phase component and the greater internal chemical pressure, both influenced by the $\mathrm{Cu}^{2+}$ substitution, appears to be determinant to interpret the obtained results.

In $\left(\mathrm{La}_{0.63} \mathrm{Ca}_{0.37}\right)\left(\mathrm{Mn}_{0.92} \mathrm{Cu}_{0.08}\right) \mathrm{O}_{3}$ the $\sigma^{2}$ parameter follows a temperature dependent Debye-like behaviour $\sigma_{\mathrm{D}}^{2}$ at high temperatures $\left(T \geq 225 \mathrm{~K}\right.$ ) with a Debye temperature $\theta_{\mathrm{D}}$ around $500 \mathrm{~K}$, plus a temperature independent static contribution $\sigma_{\mathrm{S}}^{2}=0.00183 \AA^{2}$ due to the presence of a Jahn-Teller distorted environment. The high temperature Debye-Waller factor shown in Fig. 5 has been fitted considering $\sigma^{2}(T)=\sigma_{\mathrm{D}}^{2}+\sigma_{\mathrm{S}}^{2}$, as already explained in previous papers [12,13], where the temperature dependent dynamic contribution $\sigma_{\mathrm{D}}^{2}$ is expressed as an infinite series whose first and most important terms are [19]:

$\sigma_{\mathrm{D}}^{2}=\frac{3 \hbar^{2}}{M k_{\mathrm{B}} \theta_{\mathrm{D}}}\left[\frac{1}{4}+\left(\frac{T}{\theta_{\mathrm{D}}}\right)^{2} \int_{0}^{\theta_{\mathrm{D}} / T} d x \frac{x}{e^{x}-1}\right]$

where $M$ is the mass of the diffuser atom. The fitting parameters were the static contribution $\sigma_{\mathrm{S}}^{2}$ and the Debye temperature $\theta_{\mathrm{D}}$, found to be about $510 \mathrm{~K}$, in accordance with previous experiments [12,13]. Otherwise below $T_{\mathrm{CO}}$ the $\sigma^{2}(T)$ behaviour is characteristic of a CO-like phase characterized by a breaking of the high temperature crystal symmetries [12,13].

For what concerns the $\left(\mathrm{La}_{0.25} \mathrm{Ca}_{0.75}\right)\left(\mathrm{Mn}_{0.92} \mathrm{Cu}_{0.08}\right) \mathrm{O}_{3}$ and $\left(\mathrm{La}_{0.25} \mathrm{Ca}_{0.75}\right)\left(\mathrm{Mn}_{0.97} \mathrm{Cu}_{0.03}\right) \mathrm{O}_{3}$ samples we evidence in Fig. 6, after comparison with the charge ordered $\left(\mathrm{La}_{0.25} \mathrm{Ca}_{0.75}\right) \mathrm{MnO}_{3}$, how the local order parameter $\sigma^{2}$ substantially remains charge ordering-like on a long-range scale, in agreement with the magnetization results. Clearly, in the Jahn-Teller $\mathrm{Cu}^{2+}$ substitution case the induced random impurity effect is not sufficient to reduce $\mathrm{CO}$ at a local level as occurs with non-Jahn-Teller $\mathrm{Ni}^{2+}$ or $\mathrm{Cr}^{3+}$ ions in the $x>0.50$ Ca-content range [13].

Moreover in all the samples we suggest the two Mn-O interatomic distances as an alternative model, which anyway does not exclude the single distance one [12]. Therefore, as published in pre-

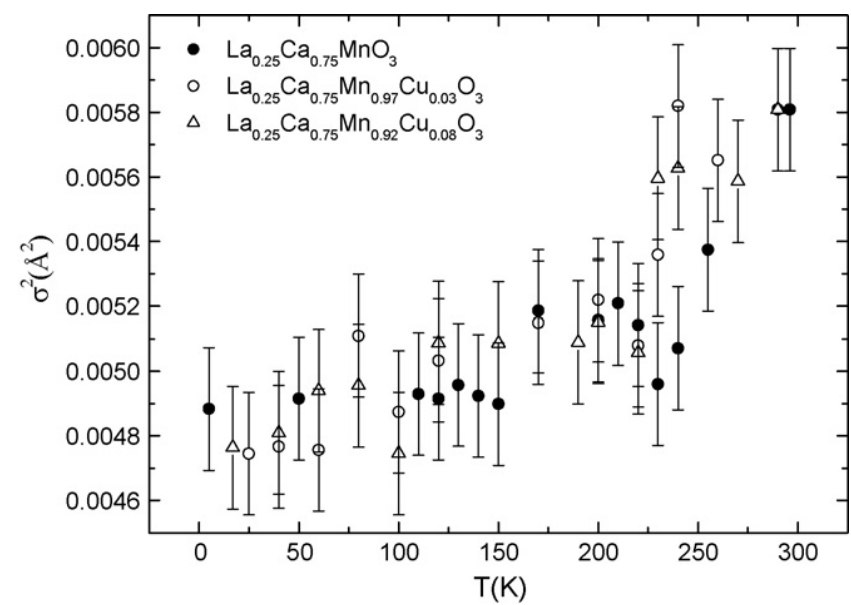

Fig. 6. $\mathrm{Mn}-\mathrm{O}$ mean square relative displacement $\sigma^{2}\left(\AA^{2}\right)$ of $\left(\mathrm{La}_{0.25} \mathrm{Ca}_{0.75}\right)$ $\left(\mathrm{Mn}_{0.92} \mathrm{Cu}_{0.08}\right) \mathrm{O}_{3}$ (empty triangles), $\left(\mathrm{La}_{0.25} \mathrm{Ca}_{0.75}\right)\left(\mathrm{Mn}_{0.97} \mathrm{Cu}_{0.03}\right) \mathrm{O}_{3}$ (empty circles) and of the pristine $\left(\mathrm{La}_{0.25} \mathrm{Ca}_{0.75}\right) \mathrm{MnO}_{3}$ sample (full circles; adapted from Ref. [11]) determined from the single shell analysis as a function of temperature.

vious papers [12,13], we distinguish a bimodal distribution of $\mathrm{Mn}-\mathrm{O}$ interatomic bond lengths, with a fit residual about 35\% lower at all temperatures than that obtained by the one shell analysis, obtaining an improvement of the fit at each temperature respect to the single shell model (see Ref. [13]). In this framework, the quality of the fit with one or two Mn-O distances was checked by means of the residual $\rho=\sum_{i} k_{i}^{3}\left[\chi_{\exp }\left(k_{i}\right)-\chi_{\text {theo }}\left(k_{i}\right)\right]^{2} / \sum_{i} k_{i}^{3}\left[\chi_{\exp }\left(k_{i}\right)\right]^{2}$, where $\chi_{\exp }\left(k_{i}\right)$ and $\chi_{\text {theo }}\left(k_{i}\right)$ are the experimental and the calculated EXAFS signals at the wave vector $k_{i}$.

The $\mathrm{Mn}-\mathrm{O}$ interatomic distances thus obtained for the sample $\left(\mathrm{La}_{0.25} \mathrm{Ca}_{0.75}\right)\left(\mathrm{Mn}_{0.92} \mathrm{Cu}_{0.08}\right) \mathrm{O}_{3}$ are reported in Fig. 7 and can be compared with the chromium doped $\left(\mathrm{La}_{0.25} \mathrm{Ca}_{0.75}\right)\left(\mathrm{Mn}_{0.92} \mathrm{Cr}_{0.08}\right) \mathrm{O}_{3}$ and un-doped $\left(\mathrm{La}_{0.25} \mathrm{Ca}_{0.75}\right) \mathrm{MnO}_{3}$ cases presented in Ref. [13]. While the partial substitution of $\mathrm{Mn}$ with $\mathrm{Cr}$ reduced the difference between longer and shorter $\mathrm{Mn}-\mathrm{O}$ distances respect to the pristine compound [13], denoting a weakening of the Jahn-Teller distortion and of the $\mathrm{CO}$ phase coherence, the Jahn-Teller Cu substitution determines an increasing of the longer $\mathrm{Mn}-\mathrm{O}$ distance and therefore accentuates the divergence between the two different sub-shell bond lengths (see also Table 1). This result confirms the presence of a local Jahn-Teller distorted and insulating phase component also

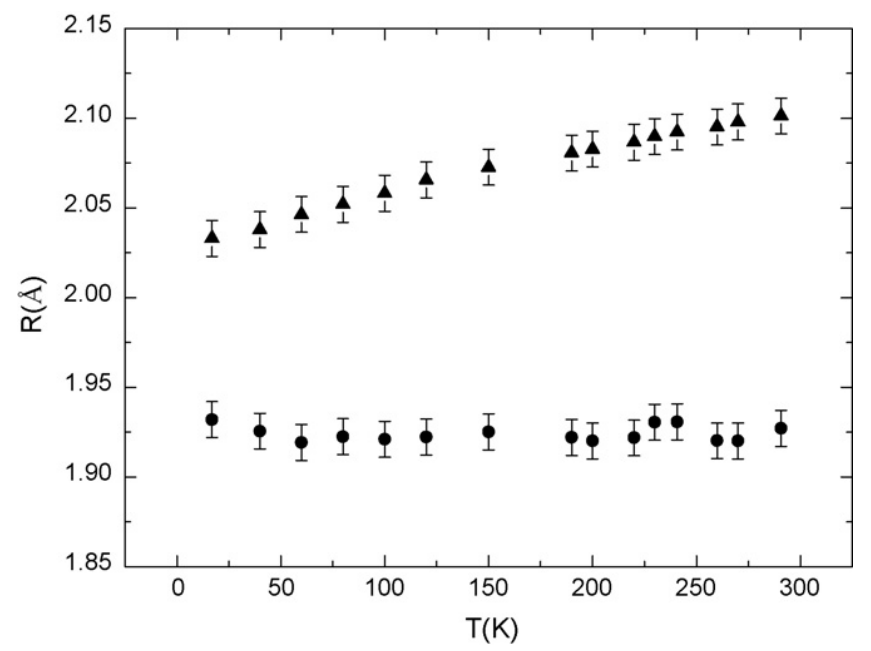

Fig. 7. Bimodal distribution of the Mn-O bond lengths $\left(N_{\mathrm{Mn}-\mathrm{O}}=4\right.$ and $N_{\mathrm{Mn}-\mathrm{O}}=2$ for the longer (full triangles) and shorter (full circles) interatomic distances) of $\left(\mathrm{La}_{0.25} \mathrm{Ca}_{0.75}\right)\left(\mathrm{Mn}_{0.92} \mathrm{Cu}_{0.08}\right) \mathrm{O}_{3}$ as a function of temperature. 


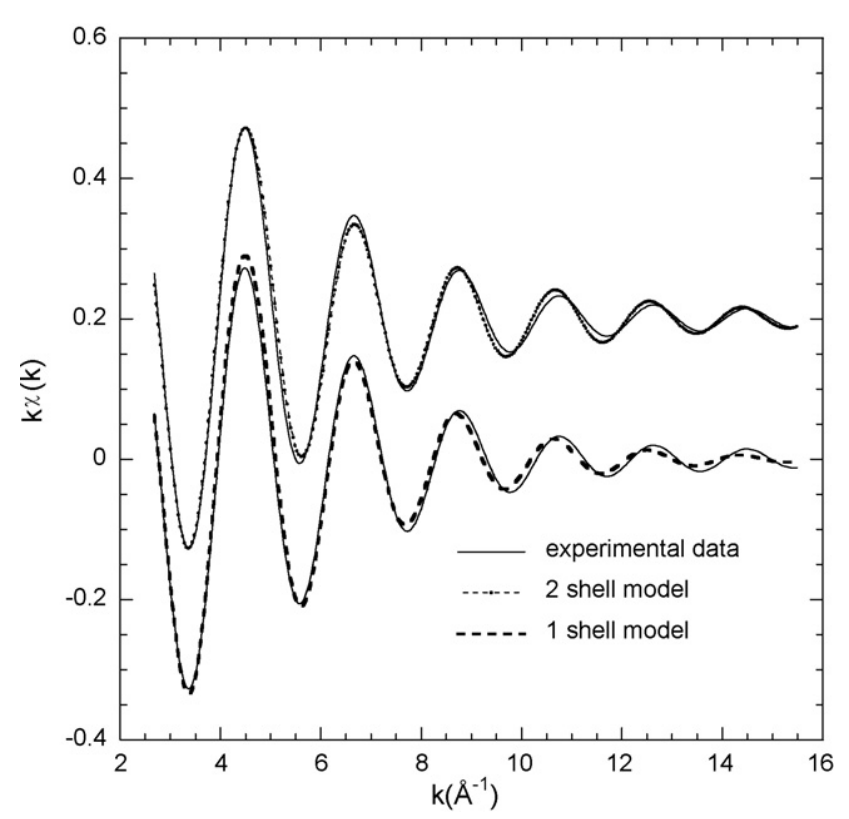

Fig. 8. Best-fit curves obtained considering one or two Mn-O distances (upper curves) for $\left(\mathrm{La}_{0.25} \mathrm{Ca}_{0.75}\right)\left(\mathrm{Mn}_{0.92} \mathrm{Cu}_{0.08}\right) \mathrm{O}_{3}$ at $300 \mathrm{~K}$; the two fit curves have been shifted for a better comprehension.

at low temperatures in the Mn substituted compounds and the significant influence on local disorder determined by the substituting ion [20].

In Fig. 8 typical fits with one or two $\mathrm{Mn}--\mathrm{O}$ distances are presented for the $\left(\mathrm{La}_{0.25} \mathrm{Ca}_{0.75}\right)\left(\mathrm{Mn}_{0.92} \mathrm{Cu}_{0.08}\right) \mathrm{O}_{3}$ sample, evidencing that the curve obtained introducing two bond lengths better reproduces the experimental data, especially at high $k$ values.

In summary, we reveal a strong correlation between the local order and structure studied by EXAFS and the magnetization behaviour and therefore we confirm a relation between charge localization (connected to local disorder), and magnetic degrees of freedom. We emphasize that a local probe like EXAFS provides information on systems that are only apparently homogeneous revealing, as in the present case, the influence of the Mn partial substitution on peculiar local scale features. Moreover in the present case, further EXAFS measurements at the $\mathrm{Cu}$ K-edge would be interesting. This should be one way to probe the $\mathrm{Cu}$ valence and to determine quantitatively the extent of distortions about the copper site.

\section{Conclusions}

We measured the EXAFS spectra and dc magnetic susceptibility of $\left(\mathrm{La}_{0.63} \mathrm{Ca}_{0.37}\right)\left(\mathrm{Mn}_{0.92} \mathrm{Cu}_{0.08}\right) \mathrm{O}_{3},\left(\mathrm{La}_{0.25} \mathrm{Ca}_{0.75}\right)\left(\mathrm{Mn}_{0.92} \mathrm{Cu}_{0.03}\right) \mathrm{O}_{3}$ and $\left(\mathrm{La}_{0.25} \mathrm{Ca}_{0.75}\right)\left(\mathrm{Mn}_{0.92} \mathrm{Cu}_{0.08}\right) \mathrm{O}_{3}$ manganites, between 20 and $300 \mathrm{~K}$. We found that the Cu substitution weakens in a relevant and outstanding way the FM long-range phase in the compound with $x<0.50$ while the CO phase in the second class of samples $(x>0.50)$ results to be only slightly conditioned. Moreover, the local structure parameters still confirm in all the studied $\mathrm{Cu}$-substituted samples the presence of the same anomalies characteristic of the $\mathrm{CO}$ pristine compounds, like the Debye-Waller factor plateau below $T_{\mathrm{CO}}$ and the Jahn-Teller splitting of the $\mathrm{Mn}-\mathrm{O}$ distances in the $\mathrm{MnO}_{6}$ octahedra.

The results we have obtained verify the natural tendency to phase separation in manganites and the possibility in the Cu substitution case, as already happened after $\mathrm{Cr}$ and Ni substitutions [13], to tune the relative weight of one phase component $(\mathrm{CO})$ respect to the other (FM) in this characteristic nanometric phase percolation scenario $[9,13]$.

\section{Acknowledgments}

The authors thank K. Klementiev for technical support at HASYLAB. This work was supported by the European Community - Research Infrastructure Action under the FP6 "Structuring the European Research Area" Programme (through the Integrated Infrastructure Initiative "Integrating Activity on Synchrotron and Free Electron Laser Science”).

\section{References}

[1] P. Schiffer, P.A. Ramirez, W. Bao, S.-W. Cheong, Phys. Rev. Lett. 75 (1995) 3336.

[2] C. Zener, Phys. Rev. 82 (1951) 403

[3] A.J. Millis, P.B. Littlewood, B.I. Shraiman, Phys. Rev. Lett. 74 (1995) 5144.

[4] J.M. De Teresa, M.R. Ibarra, P.A. Algarabel, C. Ritter, C. Marquina, J. Blasco, J. Garcia, A. del Moral, Z. Arnold, Nature 386 (1997) 256.

[5] A. Moreo, S. Yunoki, E. Dagotto, Science 283 (1999) 2034

[6] M. Fäth, S. Freisem, A.A. Menovsky, Y. Tomioka, J. Aarts, J.A. Mydosh, Science 285 (1999) 1540.

[7] F. Cordero, C. Castellano, R. Cantelli, M. Ferretti, Phys. Rev. B 65 (2002) 124031.

[8] P. Levy, F. Parisi, M. Quintero, L. Granja, J. Curiale, J. Sacanell, G. Leyva, G. Polla, R.S. Freitas, L. Ghivelder, Phys. Rev. B 65 (2002) 140401.

[9] T. Katsufuji, S.-W. Cheong, S. Mori, C.H. Chen, J. Phys. Soc. Jpn. 68 (1999) 1090.

[10] H. Oshima, Y. Ishihara, M. Nakamura, K. Miyano, Phys. Rev. B 63 (2001) 094420 (and references therein).

[11] B. Raveau, Philosoph. Trans. Royal Soc. A 366 (2008) 83 (and references therein).

[12] C. Castellano, A. Paolone, F. Cordero, R. Cantelli, M. Ferretti, Solid State Commun. $129(2004) 143$.

[13] C. Castellano, F. Cordero, O. Palumbo, R. Cantelli, R. Cimberle, M. Tropeano, A Martinelli, M. Ferretti, Solid State Commun. 136 (2005) 244.

[14] B. Lengeler, P. Eisenberger, Phys. Rev. B 21 (1980) 4507.

[15] A.L. Ankudinov, B. Ravel, J.J. Rehr, S.D. Conradson, Phys. Rev. B 58 (1998) 7565.

[16] Lei Zheng, X. Xu, Li Pi, Y. Zhang, Phys. Rev. B 62 (2000) 1193.

[17] C.H. Booth, J. Bridges, G.H. Kwei, J.M. Lawrence, A.L. Cornelius, J.J. Neumeier, Phys. Rev. B 57 (1998) 10440.

[18] A. Lanzara, N.L. Saini, M. Brunelli, F. Natali, A. Bianconi, P.G. Radaelli, S.-W. Cheong, Phys. Rev. Lett. 81 (1998) 878.

[19] G. Beni, P.M. Platzmann, Phys. Rev. B 14 (1976) 1514.

[20] D. Cao, F. Bridges, M. Anderson, A.P. Ramirez, M. Olapinski, M.A. Subramanian, C.H. Booth, G.H. Kwei, Phys. Rev. B 64 (2001) 184409. 